\title{
Alternative promoter activation leads to the expression of a novel human lysyl oxidase variant that functions as an amine oxidase
}

\author{
SEONKWAN KIM, SUNHYANG PARK and YOUNGHO KIM
}

Department of Biochemistry, Wonkwang University School of Medicine, Iksan, Jeollabuk-Do 570-749, Republic of Korea

Received March 17, 2014; Accepted June 27, 2014

DOI: $10.3892 / \mathrm{ijmm} .2014 .1845$

\begin{abstract}
The lysyl oxidase (LOX) family is an emerging family of amine oxidases that is responsible for lysine-mediated crosslinks found in collagen and elastin. Several novel functions, such as tumor suppression, tumor progression, cellular senescence, chemotaxis and the modification of histones have recently been attributed to the LOX family of proteins. In the search for more human LOX paralogs, in the present study, we identified several expressed sequence tag (EST) clones that showed an alternative exon-intron splice pattern from $L O X$. These ESTs corresponded to the $L O X$ transcript variant $2(L O X-v 2)$ that was recently reported in GenBank (accession no. NM_001178102). LOX-v2 mRNA lacks exon 1 of $L O X$, but contains an additional 222 bp sequence from the 5'-flanking intronic region of exon 2. The deduced $L O X-v 2$ polypeptide contains the characteristic C-terminal domains of the LOX family, but does not contain the $\mathrm{N}$-terminal propeptide region that has been reported to have tumor suppressor activity. In peroxidase-coupled fluorometric assays, LOX-v2 showed $\beta$-aminopropionitrile-inhibitable amine oxidase activity toward collagen and elastin. RT-PCR analysis of human tissues revealed a distinct tissue specificity of $L O X-v 2$ expression compared to that of $L O X$. Promoter assays indicated that an alternative promoter element present in the exon 1 region of $L O X$ was sufficient for the differential expression of $L O X-v 2$. These findings indicate that the human $L O X$ gene encodes 2 variants, LOX and LOX-v2, both of which function as amine oxidases with distinct tissue specificities.
\end{abstract}

\section{Introduction}

Lysyl oxidase (LOX) is a copper-dependent amine oxidase that is responsible for the post-translational modification of collagen and elastin by oxidizing peptidyl lysines to $\alpha$-aminoadipic

Correspondence to: Dr Youngho Kim, Department of Biochemistry, Wonkwang University School of Medicine, Sinyong-Dong 344-2, Iksan, Jeollabuk-Do 570-749, Republic of Korea

E-mail: youngkim@wonkwang.ac.kr

Key words: lysyl oxidase, variant, amine oxidase, alternative promoter, differential expression $\delta$-semialdehydes, also known as allysines $(1,2)$. The peptidyl aldehydes then undergo spontaneous condensation with unreacted $\varepsilon$-amino groups or neighboring aldehyde groups of the lysine residues to form covalent cross-linkages found in collagen and elastin fibers $(1,2)$. This essential role of LOX in the biogenesis of connective tissues qualifies the enzyme as a potentially pivotal target for the development of therapeutic strategies for diseases associated with extracellular matrix remodeling.

Five proteins of the LOX family (LOX, LOXL1, LOXL2, LOXL3 and LOXL4) have been identified in humans, each containing the characteristic C-terminal domains of the LOX family, such as a copper-binding domain, residues for lysyl-tyrosyl quinone (LTQ), and a cytokine receptor-like (CRL) domain (3-7). In addition to the crosslinking activity on collagen and elastin, several novel functions of the LOX family have been revealed, including tumor suppression $(8,9)$, tumor progression (10-12), chemotaxis (13) and the modification of histone proteins (14-16). Thus, the presence of a $L O X$ gene family suggests that the differential regulation of the $L O X$ paralogs may lead to diverse functions, most of which are currently assigned to LOX.

In search for more human $L O X$ paralogs, we identified several expressed sequence tag (EST) clones that showed an alternative exon-intron splice pattern from $L O X$. These ESTs corresponded to a novel variant, $L O X$ transcript variant 2 ( $L O X-v 2)$, which lacks exon 1 of $L O X$ and encodes a 188 amino acid-long polypeptide of $22 \mathrm{kDa}$. In this study, we report that LOX-v2 functions as an amine oxidase toward collagen and elastin, but with distinct tissue specificity from $L O X$. An alternative promoter element present in the exon 1 region of $L O X$ may be responsible for the differential transcriptional regulation of $L O X-v 2$.

\section{Materials and methods}

EST database search. The human LOX cDNA sequence (GenBank accession no. NM_002317) was used to search the human EST database using the BLASTN program (http://www.ncbi.nlm.nih.gov/cgi-bin/BLAST).

RT-PCR analysis in human tissues. Human Multiple Tissue cDNA panels (Clontech, Mountain View, CA, USA) were PCR-amplified with primers specific to $L O X$ and $L O X-v 2$ using Ex Taq polymerase (Takara Bio, Inc., Shiga, Japan). The $L O X$-specific forward primer was 5'-GATACGGCACTGG 
CTACTTC-3' and the $L O X-v 2$-specific forward primer was 5'-AGGAGTAAGGGACCTAGAGG-3'. A common reverse primer (5'-GAATATCTTGGTCGGCTGGG-3') was used for both $L O X$ and $L O X-v 2$ specific amplicons. The $L O X$-specific primers were designed to amplify the region corresponding to the nucleotide sequence 980-1229 of $L O X$, while the $L O X-v 2$ specific primers were designed to amplify the region which corresponded to the $136-445$ bp region of the $L O X-v 2$ nucleotide sequence. The PCR conditions consisted of 30 cycles at $94^{\circ} \mathrm{C}$ for $30 \mathrm{sec}, 58^{\circ} \mathrm{C}$ for $30 \mathrm{sec}$ and $72^{\circ} \mathrm{C}$ for $30 \mathrm{sec}$ with a predenaturation at $94^{\circ} \mathrm{C}$ for $4 \mathrm{~min}$ and a final extension at $72^{\circ} \mathrm{C}$ for $5 \mathrm{~min}$. The amplified PCR products were analyzed by electrophoresis on a $2 \%$ agarose gel. The glyceraldehyde 3-phosphate dehydrogenase $(G A P D H)$ gene was used as an internal control. All RT-PCR analyses were performed in the linear range of amplification, and quantification was performed using a Kodak Gel Logic Imaging System (Eastman Kodak, Rochester, NY, USA).

Expression and purification of $L O X$ and $L O X-v 2$ proteins. Using the previously reported pET21a-LOX-p construct (17) as a PCR template, the entire coding region of $L O X-v 2$ was PCR-amplified by $P f u$ turbo polymerase (Agilent Technologies, Santa Clara, CA, USA) according to the instructions of the manufacturer. The sequences of the oligonucleotide primers used for the construction of the expression plasmids were 5'-GCGGCTAGCATGTCCATGTACAACCTGAG-3' and 5'-GCGAAGCTTATACGGTGAAATTGTGCAGC-3'. A unique restriction site, either NheI or HindIII, was introduced in each primer for convenient subcloning. The PCR conditions consisted of 30 cycles at $94^{\circ} \mathrm{C}$ for $60 \mathrm{sec}, 56^{\circ} \mathrm{C}$ for $60 \mathrm{sec}$ and $72^{\circ} \mathrm{C}$ for $60 \mathrm{sec}$ with a predenaturation at $94^{\circ} \mathrm{C}$ for $4 \mathrm{~min}$ and a final extension at $72^{\circ} \mathrm{C}$ for $7 \mathrm{~min}$. The sequence of the resulting expression constructs were confirmed by DNA-sequencing analysis using a Cycle Sequencing Ready Reaction kit (Life Technologies, Paisley, UK) according to the manufacturer's instructions. The E. coli strain BL21 (DE3) (Novagen, Madison, WI, USA) was used for transformation of the LOX or LOX-v2 expression constructs. The recombinant proteins were expressed, purified, and refolded into an enzymatically active form as previously reported (17).

Amine oxidase assays. The amine oxidase activity of the LOX and LOX-v2 recombinant proteins was assessed using a peroxidase-coupled fluorometric assay with the Amplex red hydrogen peroxide assay kit (Molecular Probes, Eugene, OR, USA) as previously described (18). Each reaction contained $10 \mu \mathrm{g}$ of purified LOX or LOX-v2 recombinant protein and 20 pmol of substrate in a reaction volume of $200 \mu \mathrm{l}$. Parallel assays were performed in the absence or presence of $1 \mathrm{mM}$ $\beta$-aminopropionitrile (BAPN) for $1 \mathrm{~h}$ at $37^{\circ} \mathrm{C}$. Bovine neck ligament elastin and calfskin type I collagen (Sigma-Aldrich, St. Louis, MO, USA) were used as substrates for the amine oxidase assays. Fluorescence was measured using a fluorescence spectrophotometer (Molecular Devices, Sunnyvale, CA, USA) with excitation and emission wavelengths of 500 and $650 \mathrm{~nm}$, respectively. Total amine oxidase activity was expressed as $\mathrm{nM}$ of $\mathrm{H}_{2} \mathrm{O}_{2}$ produced per $\mu \mathrm{g}$ of LOX or LOX-v2 recombinant protein, calculated by interpolation with fluorescence values from an $\mathrm{H}_{2} \mathrm{O}_{2}$ calibration curve.
Promoter analysis. For the construction of reporter plasmids, the 5'-flanking regions of exons 1 and 2 of LOX were separately PCR-amplified from human genomic DNA using Ex Taq polymerase (Takara Bio, Inc.). For $L O X$ promoter assays, a 1,424 bp fragment from nucleotide position +112 to -1312 was amplified. For $L O X-v 2$ promoter assays, a series of DNA fragments of 1,044, 792 and $169 \mathrm{bp}$, each corresponding to the 5'-flanking region of exon 2 of $L O X$, was generated. The sequences of the oligonucleotide primers used are available upon request. The PCR-amplified genomic DNA fragments were ligated into a promoterless luciferase reporter plasmid pGL3-basic (Promega, Madison, WI, USA). Promoter assays were performed on HEK 293 cells as previously described (19). The pGL3-SV plasmid containing the strong T-antigen promoter of SV40 was used as a positive control for the assays, while a promoterless plasmid pGL3-Basic was used as a negative control. The luciferase activity of each construct was expressed as a ratio to that of the promoterless control. All transfections were performed in quadruplicate. The results are expressed as the means \pm standard deviation (SD).

\section{Results}

Distinct exon-intron structure of $L O X-v 2$ from $L O X$. A search of the human EST databases for sequences similar to the human $L O X$ gene resulted in the identification of several ESTs (AW958146, AL598579, BP205326, DA655672, DA720490 and DA883598). These ESTs showed a distinct exon-intron splice pattern from $L O X$ and corresponded to human $L O X-v 2$ that was recently reported in GenBank (accession no. NM_001178102). Exon-intron structure analysis of $L O X-v 2$ revealed that this novel variant is composed of 6 exons, lacking exon 1 of $L O X$ (Fig. 1A). At the 5'-end, $L O X-v 2$ mRNA contains an additional 222 bp sequence from the 5'-flanking intronic region of exon 2 of LOX (Fig. 1A).

The $L O X-v 2$ mRNA is at least 4,393 bp in length, encoding a 187 amino acid-long polypeptide with a calculated molecular mass of $21.6 \mathrm{kDa}$. The 5 '-UTR of the $L O X-v 2$ mRNA is at least $281 \mathrm{bp}$ in length. The coding region is $564 \mathrm{bp}$ and the 3'-UTR is 3,548 bp with at least 3 poly(A) signals. The methionine at codon 231 in $L O X$ was used as the initiation codon in the deduced amino acid sequence of LOX-v2 (Fig. 1B). The deduced LOX-v2 polypeptide contains the characteristic C-terminal domains of the LOX family, including the copperbinding domain, the residues for the LTQ cofactor, and the CRL domain, but does not contain the N-terminal propeptide region that corresponds to codons $\mathrm{Met}^{1}$ to Gly ${ }^{168}$ (Fig. 1B).

\section{Different tissue-specificity of LOX and LOX-v2 in human} tissue. To compare the expression of $L O X$ and $L O X-v 2$ in human tissue, RT-PCR was performed with poly (A) ${ }^{+}$RNA isolated from 16 different human tissues. The forward primer for the $L O X$-specific amplicon was derived from exon 1 of $L O X$, which was deleted in the $L O X-v 2$ mRNA. By contrast, the forward primer for the $L O X-v 2$-specific amplicon was derived from the 5'-flanking intronic region of exon 2 of $L O X$, which was included in the $L O X-v 2 \mathrm{mRNA}$, but not in the $L O X$ mRNA. A reverse primer from exon 3 of $L O X$ was used for both $L O X$ - and $L O X$-v2-specific PCR amplicons. In general, the expression of $L O X-v 2$ was lower than that of 


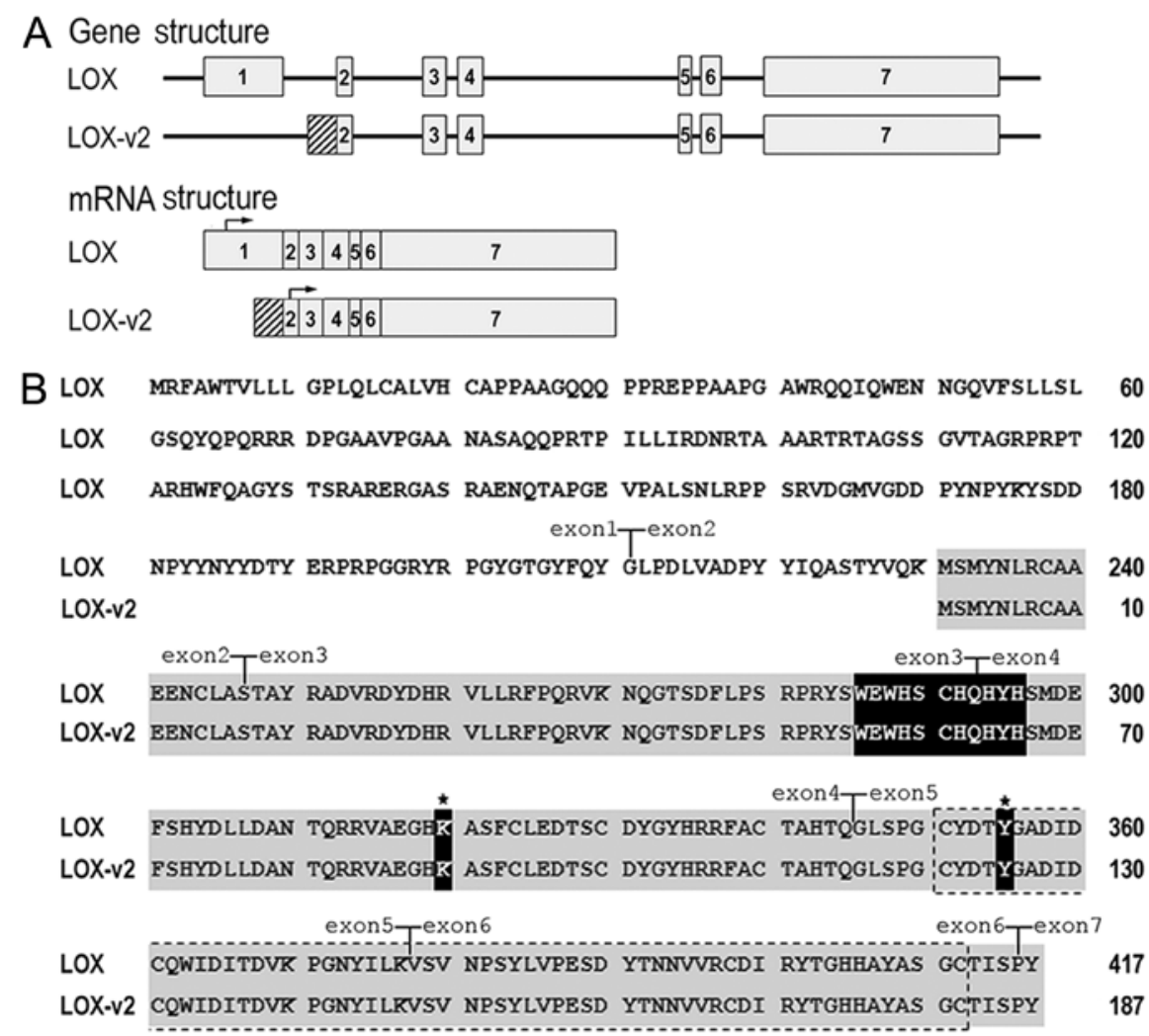

Figure 1. Exon-intron structure and deduced amino acid sequence of lysyl oxidase transcript variant 2 ( $L O X-v 2)$. (A) Comparison of the exon-intron and mRNA structure of $L O X$ and $L O X-v 2$. Exons are shown as gray boxes, introns as bold lines. In $L O X$ - $v 2$, the hatched box indicates the additional 222 bp sequence corresponding to the 5'-flanking intronic region of exon 2 of $L O X$. The translation initiation sites are indicated by an arrow in each mRNA variant. (B) Amino acids are indicated as a single letter code and numbered from the N-terminal end. The conserved amino acid residues are indicated by shading. The copperbinding motif is indicated in reverse-font letters in a box of darker shading, the lysyl-tyrosyl quinone (LTQ) residues in reverse-font letters with an asterisk mark, and the cytokine receptor-like (CRL) domain in a box with dashed lines. The exon junctions are indicated by T-bars.

$L O X$ in most tissues tested, but there were some differences in expression patterns. For instance, the $L O X$-specific band was more ubiquitously detected in the tissues tested apart from the brain and leukocytes, whereas the $L O X-v 2$-specific band was observed in a more tissue-specific pattern, showing relatively higher levels in the lungs, kidneys, spleen, ovaries and small intestine (Fig. 2).

Amine oxidase activity of LOX-v2. To determine whether LOX-v2 functions as an amine oxidase, we expressed and purified the LOX-v2 protein in a hexa-histidine recombinant form as previously described for LOX and other LOX family proteins $(17,19,20)$ (Fig. 3A). For comparison with LOX for amine oxidase activity, the LOX protein was also expressed and purified in a hexa-histidine recombinant form as previously reported (17). The apparent sizes of the purified recombinant proteins were in agreement with the deduced molecular mass; 32 and $24 \mathrm{kDa}$ for the recombinant LOX and LOX-v2 proteins, respectively (Fig. 3B).

The recombinant LOX and LOX-v2 proteins were assessed for amine oxidase activity toward collagen type I and elastin using a peroxidase-coupled fluorometric assay. Both the recombinant LOX and LOX-v2 proteins showed significant levels of amine oxidase activity toward both collagen type I and elastin. The amine oxidase activity of LOX and LOX-v2 was sensitive to BAPN, an irreversible inhibitor of LOX (Fig. 3C). The LOX protein showed a slightly higher amine oxidase activity than the LOX-v2 protein; however, the difference was not statistically significant (Fig. 3C). These results indicate that LOX-v2 also functions as an amine oxidase toward physiological substrates of LOX, such as collagen type I and elastin.

An alternative promoter for the expression of $L O X-v 2$. To establish whether the 5'-flanking region of exon 2 of $L O X$ is sufficient for transcriptional initiation of $L O X-v 2$, a series of promoter reporter constructs was generated, each containing a different portion of the 5'-proximal genomic region of exon 2 (Fig. 4A). The 5'-flanking genomic region of exon 1 of $L O X$ was also examined for comparison. In the HEK 293 cells, the $L O X$ promoter construct containing a 1,424 bp fragment of the 5'-proximity of exon 1 showed approximately 45 -fold higher promoter activity than the promoterless negative control (Fig. 4B). The $L O X$-v2-promoter constructs 1 and 2, each containing a 1,044 or $792 \mathrm{bp}$ fragment of the 5'-proximal region of exon 2 of $L O X$, respectively, showed 11 to 12 -fold higher promoter activities than the negative control (Fig. 4B). By contrast, the $L O X-v 2$-promoter construct 3 containing a 169 bp fragment of the 5'-proximal region of exon 2 of $L O X$ showed no detectable promoter activity (Fig. 4B). These results indicate that an alternative promoter element required for the transcriptional activation of $L O X-v 2$ may reside in the region corresponding to exon 1 of $L O X$, although the promoter activity of this alternative promoter is significantly weaker than that of the promoter required for the transcriptional activation of 


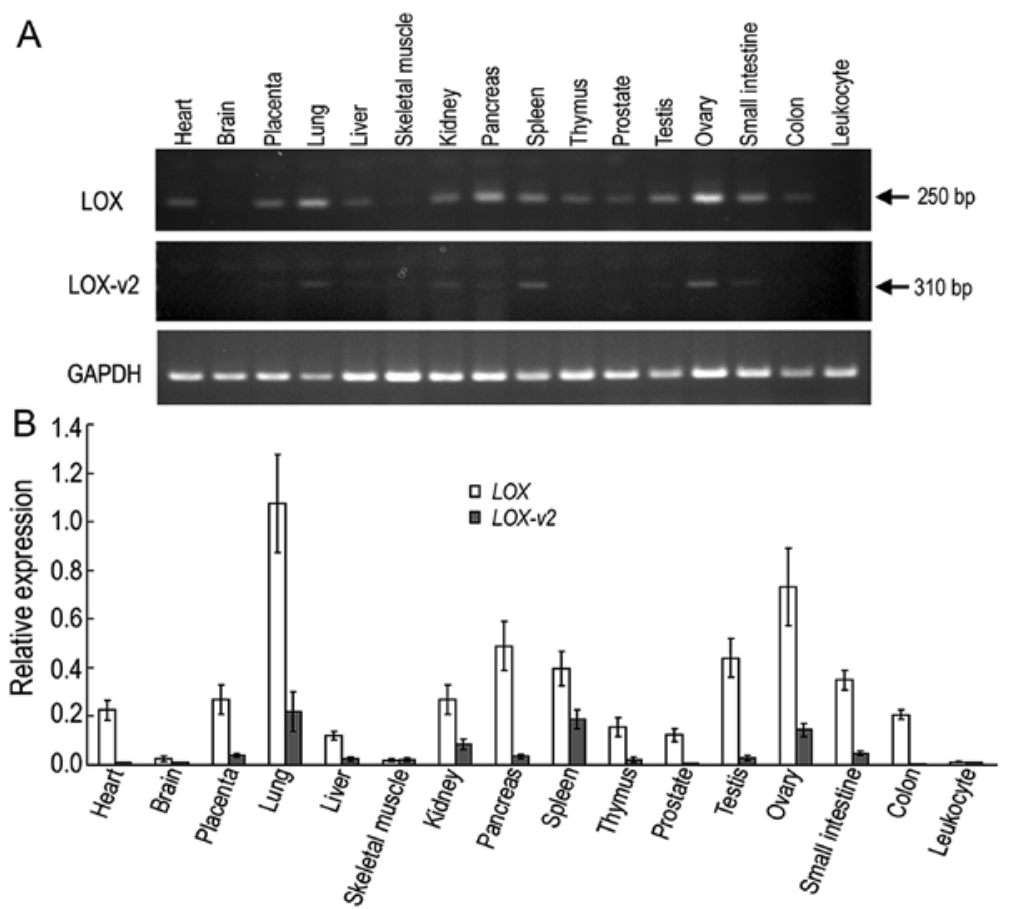

Figure 2. RT-PCR of lysyl oxidase ( $L O X)$ and $L O X$ transcript variant $2(L O X-v 2)$ in human tissues. (A) A typical example of RT-PCR of $L O X$ and $L O X-v 2$ using poly $(\mathrm{A})^{+} \mathrm{RNA}$ from 16 different human tissues. The analysis was repeated in triplicate, and all analyses showed similar expression patterns. Expected band sizes of 250 and 310 bp were detected in RT-PCR for the $L O X$ - and $L O X$-v2-specific amplicons, respectively. Glyceraldehyde 3-phosphate dehydrogenase $(G A P D H)$ was used as an internal control. (B) The intensities of the PCR amplicons of $L O X$ and $L O X-v 2$ were expressed as a densitometric ratio to the intensity of the GAPDH amplicon. The white and gray bars indicate relative intensities of $L O X$ and $L O X-v 2$ bands, respectively. The standard deviation is indicated on the graph.

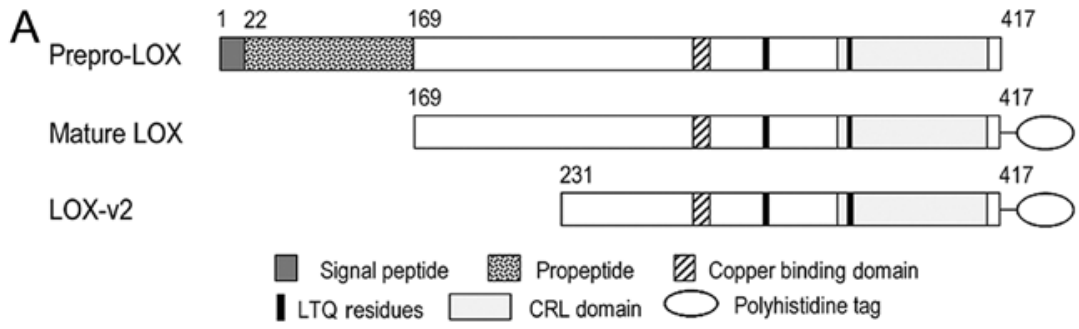

B

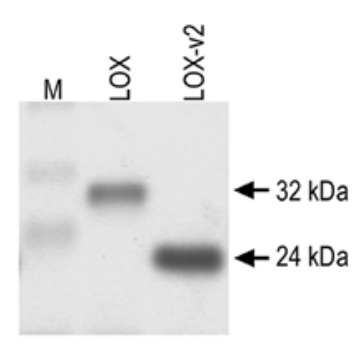

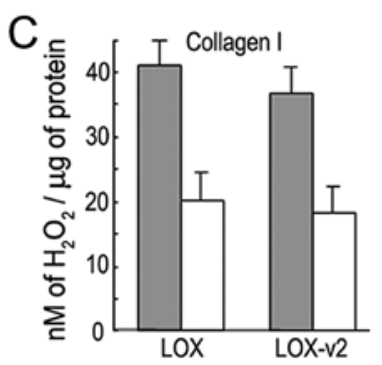

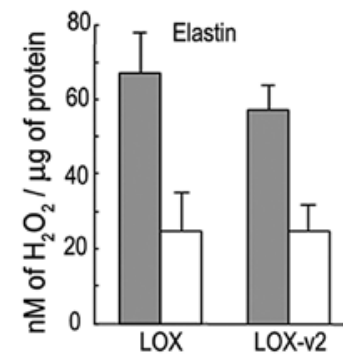

Figure 3. Amine oxidase activity of lysyl oxidase (LOX) and LOX transcript variant 2 (LOX-v2). (A) Schematic diagrams of the recombinant LOX and LOX-v2 proteins. (B) The recombinant LOX and LOX-v2 proteins were expressed as recombinant proteins of 32 and $24 \mathrm{kDa}$ with a hexa-histidine tag at the C-terminus, respectively. (C) The amine oxidase assays were repeated in quadruplicate. The amine oxidase activity was expressed as $\mathrm{nM}$ of $\mathrm{H}_{2} \mathrm{O}_{2}$ produced per $\mu \mathrm{g}$ of the LOX or LOX-v2 recombinant protein. The gray and white bars indicate the reactions without and with $\beta$-aminopropionitrile (BAPN), respectively. Standard deviations are indicated on the graph.

$L O X$. Both $L O X$ and $L O X-v 2$ promoter regions contained no typical canonical elements, TATA and CAAT boxes, in the proximity of the transcription initiation site, but displayed high CpG-rich sequences, as previously obsered in other $L O X$ family genes $(4,5,19)$.

\section{Discussion}

From the time of the discovery of LOX in 1968 (21), its molecular weight has remained uncertain as this enzyme tends to extensively aggregate during purification. Utilization of urea extraction 


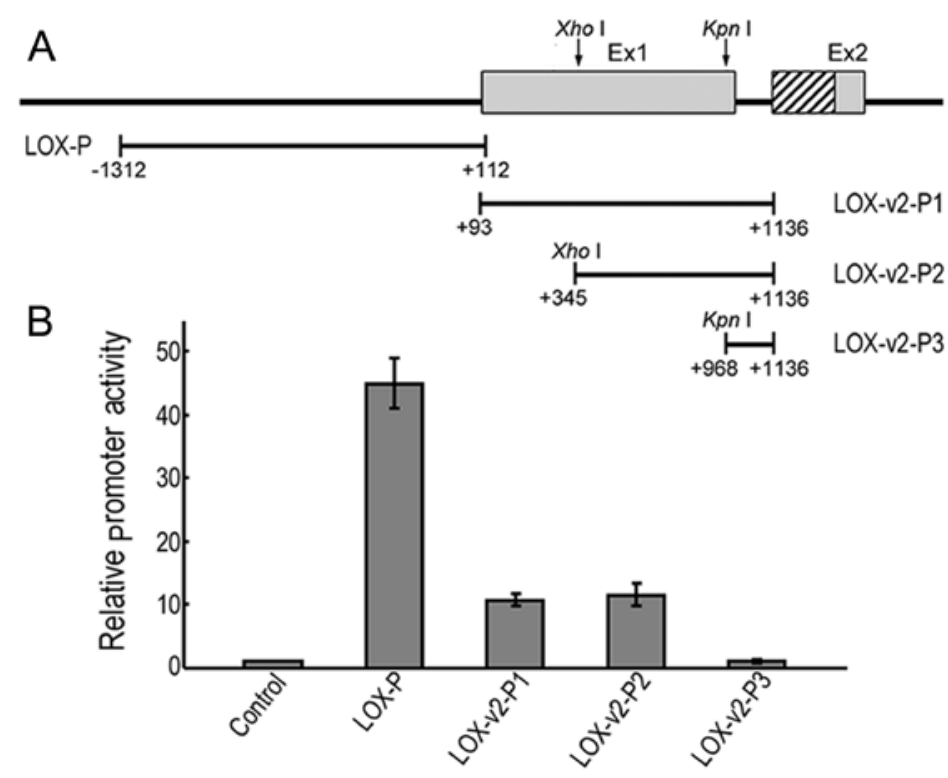

Figure 4. Analysis of the promoter activity of the 5'-proximal region of exon 2 of lysyl oxidase (LOX). (A) A schematic diagram of the promoter regions of $L O X$ and $L O X$ transcript variant $2(L O X-v 2)$. The LOX-v2-P1, -P2 and -P3 promoter constructs were derived from the 5'-upstream region of exon 2, each containing a 1,044, 792 and 169 bp sequence, respectively. The LOX-P constructs contained a 1,412 bp fragment from the 5'-proximal region of exon 1 of $L O X$. The nucleotide positions are indicated at each construct. (B) Promoter assays were repeated in quadruplicate using a luciferase reporter system. The promoter activity of each construct was expressed as a ratio to the activity of the promoterless pGL3-Basic. The standard deviation is indicated on the graph.

buffers has allowed for the isolation of chromatographically distinct variants of LOX with a molecular weight varying from 28 to $32 \mathrm{kDa}$, which showed subtle differences in amino acid compositions (22-24). Four LOX-like genes (LOXL1-4) have been identified, each encoding the characteristic C-terminal domains of LOX; however, the expected molecular weights of these LOX-like proteins were significantly larger $(63-87 \mathrm{kDa})$ than the molecular weight of the secreted mature LOX (4-7). These findings suggested that the previously identified LOX variants were neither derived from post-translational modifications of the LOX precursor nor encoded by different genes. Furthermore, smaller sizes of LOX ranging from 24 to $28 \mathrm{kDa}$ have been observed in various cultured cells and tissues. A $24 \mathrm{kDa}$ band was observed in chromatographically purified fractions of bovine aorta (23) and a 25-28 kDa band was detected in the nuclear extract of rat aorta smooth muscle cells (25), adding even more puzzling complexity on the size of the mature form of LOX. Thus, the identification of LOX-v2 may suggest that the smaller sizes of LOX previously identified may be derived, at least in part, from LOX-v2 that is expressed by an alternative promoter located in the $L O X$ gene.

The human LOX precursor is synthesized as a $48 \mathrm{kDa}$ preproprotein of 417 amino acids and following cleavage of the signal peptide composed of 21 amino acids, the proprotein undergoes extensive post-translational modifications throughout the secretion pathway (26). After being secreted into the extracellular space, the propeptide region of 147 amino acids is cleaved off by bone morphogenic protein-1 (BMP-1) between residues Gly $^{168}$ and $\mathrm{Asp}^{169}$, resulting in an enzymatically active $32 \mathrm{kDa}$ protein of 249 amino acids (26). Previous studies have reported that LOX is not only secreted in the extracellular matrix, but is also present in intranuclear locations, suggesting a novel function for LOX in the alteration of chromatin structure and the modification of histone proteins $(25,27,28)$. The absence of the propeptide region in LOX-v2 suggests that this novel variant of LOX may be subject to different cellular processing and post-translational modification from LOX, playing a distinct functional role in different cellular compartments.

Since the discovery that $L O X$ functions as the ras recision gene in the phenotypic reversion of ras-transformed cells (8), perplexing expression patterns of $L O X$ have been observed in various neoplastic tissues and cells. $L O X$ upregulation has been detected in breast (29) and renal cell carcinomas (30), while $L O X$ downregulation has been observed in prostate (31), bronchogenic (32) and gastric carcinomas (33). Furthermore, the upregulation of $L O X$ is more evident in invasive cells of breast carcinomas than in non-metastatic cells (34). These results suggest that $L O X$ plays paradoxical roles in the suppression or progression of tumorigenesis, depending on tumor status and type. In its role as a tumor suppressor, the propeptide domain of LOX, not the C-terminal domains, has been shown to inhibit ras-dependent cell transformation (35). Furthermore, the propeptide domain has been reported to reduce the invasive phenotype of Her-2/neudriven breast cancer cells (36), to inhibit the fibronectin-mediated activation of focal adhesion kinase in breast cancer cells (37), and to interfere with fibroblast growth factor-2-induced proliferation in prostate cancer cells (38). By contrast, the proteolytically processed $32 \mathrm{kDa}$ LOX that does not contain the propeptide region has been shown to play a pivotal role in the hypoxiainduced metastasis of breast and head and neck carcinomas (10). Thus, the non-existence of the propeptide domain in LOX-v2 may lead to a plausible hypothesis that the tumor progression activity currently assigned to LOX may be attributed, at least to a certain extent, to LOX-v2, while LOX with the propeptide domain may be more associated with tumor suppression. Depending on the cell status and signals, the $L O X$ gene may be subject to alternative promoter activation, resulting in either $L O X$ or $L O X-v 2$ mRNA, which may function as a regulatory mechanism for determining the functional role of LOX in tumorigenesis. Studies on cellular processing and the compartmentalization of LOX-v2 along with 
detailed expression analysis in various tumor types are required in order to determine the specific functional roles of LOX-v2, which may help broaden our understanding of the perplexing functional roles of LOX in tumorigenesis.

\section{Acknowledgements}

This study was supported by a grant from the National Research Foundation (NRF) of Korea funded by the Ministry of Education, Science and Technology (2011-0030130).

\section{References}

1. Kagan HM and Trackman PC: Properties and function of lysyl oxidase. Am J Respir Cell Mol Biol 5: 206-210, 1991.

2. Smith-Mungo LI and Kagan HM: Lysyl oxidase: Properties, regulation and multiple functions in biology. Matrix Biol 16: 387-398, 1998.

3. Hämäläinen ER, Jones TA, Sheer D, Taskinen K, Pihlajaniemi T and Kivirikko KI: Molecular cloning of human lysyl oxidase and assignment of the gene to chromosome 5q23.3-31.2. Genomics 11: 508-516, 1991

4. Kim Y, Boyd CD and Csiszar K: A new gene with sequence and structural similarity to the gene encoding human lysyl oxidase. J Biol Chem 270: 7176-7182, 1995.

5. Jourdan-Le Saux C, Tronecker H,Bogic L,Bryant-Greenwood GD, Boyd CD and Csiszar K: The LOXL2 gene encodes a new lysyl oxidase-like protein and is expressed at high levels in reproductive tissues. J Biol Chem 274: 12939-12944, 1999.

6. Mäki JM and Kivirikko KI: Cloning and characterization of a fourth human lysyl oxidase isoenzyme. Biochem J 355: 381-387, 2001.

7. Asuncion L, Fogelgren B, Fong KS, Fong SF, Kim Y and Csiszar K: A novel human lysyl oxidase-like gene (LOXL4) on chromosome 10q24 has an altered scavenger receptor cysteine rich domain. Matrix Biol 20: 487-491, 2001.

8. Kenyon K, Contente S, Trackman PC, Tang J, Kagan HM and Friedman RM: Lysyl oxidase and rrg messenger RNA. Science 253: 802,1991

9. Giampuzzi M, Botti G, Cilli M, Gusmano R, Borel A, Sommer P and Di Donato A: Down-regulation of lysyl oxidase-induced tumorigenic transformation in NRK-49F cells characterized by constitutive activation of ras proto-oncogene. J Biol Chem 276 29226-29232, 2001

10. Erler JT, Bennewith KL, Nicolau M, Dornhöfer N, Kong C, LeQT, Chi JT, Jeffrey SS and Giaccia AJ: Lysyl oxidase is essential for hypoxia-induced metastasis. Nature 440: 1222-1226, 2006.

11. Schietke R, Warnecke C, Wacker I, Schödel J, Mole DR, Campean V, Amann K, Goppelt-Struebe M, Behrens J, Eckardt KU and Wiesener MS: The lysyl oxidases LOX and LOXL2 are necessary and sufficient to repress E-cadherin in hypoxia: insights into cellular transformation processes mediated by HIF-1. J Biol Chem 285: 6658-6669, 2010.

12. Peinado H, Del Carmen Iglesias-de la Cruz M, Olmeda D, Csiszar K, Fong KS, Vega S, Nieto MA, Cano A and Portillo F: A molecular role for lysyl oxidase-like 2 enzyme in snail regulation and tumor progression. EMBO J 24: 3446-3458, 2005.

13. Lucero HA, Ravid K, Grimsby JL, Rich CB, DiCamillo SJ, Mäki JM, Myllyharju J and Kagan HM: Lysyl oxidase oxidizes cell membrane proteins and enhances the chemotactic response of vascular smooth muscle cells. J Biol Chem 283: 24103-24117, 2008.

14. Kagan HM, Williams MA, Calaman SD and Berkowitz EM: Histone $\mathrm{H} 1$ is a substrate for lysyl oxidase and contains endogenous sodium borotritide-reducible residues. Biochem Biophys Res Commun 115: 186-192, 1983.

15. Giampuzzi M, Oleggini R and Di Donato A: Demonstration of in vitro interaction between tumor suppressor lysyl oxidase and histones $\mathrm{H} 1$ and $\mathrm{H} 2$ : definition of the regions involved. Biochim Biophys Acta 1647: 245-251, 2003.

16. Herranz N, Dave N, Millanes-Romero A, Morey L, Díaz VM, Lórenz-Fonfría V, Gutierrez-Gallego R, Jerónimo C, Di Croce L, García de Herreros A and Peiró S: Lysyl oxidase-like 2 deaminates lysine 4 in histone H3. Mol Cell 46: 369-376, 2012.

17. Jung ST, Kim MS, Seo JY, Kim HC and Kim Y: Purification of enzymatically active human lysyl oxidase and lysyl oxidase-like protein from Escherichia coli inclusion bodies. Protein Expr Purif 31: 240-246, 2003.
18. Palamakumbura AH and Trackman PC: A fluorometric assay for detection of lysyl oxidase enzyme activity in biological samples. Anal Biochem 300: 245-251, 2002.

19. Lee JE and Kim Y: A tissue-specific variant of the human lysyl oxidase-like protein 3 (LOXL3) functions as an amine oxidase with substrate specificity. J Biol Chem 281: 37282-37290, 2006.

20. Kim MS, Kim SS, Jung ST, Park JY, Yoo HW, Ko J, Csiszar K, Choi SY and Kim Y: Expression and purification of enzymatically active forms of the human lysyl oxidase-like protein 4 . J Biol Chem 278: 52071-52074, 2003.

21. Pinnell SR and Martin G: The cross-linking of collagen and elastin: enzymatic conversion of lysine in peptide linkage to alpha-aminoadipic-delta-semialdehyde (allysine) by an extract from bone. Proc Natl Acad Sci USA 61: 708-716, 1968.

22. Kagan HM, Sullivan KA, Olsson TA III and Cronlund AL: Purification and properties of four species of lysyl oxidase from bovine aorta. Biochem J 177: 203-214, 1979.

23. Sullivan KA and Kagan HM: Evidence for structural similarities in the multiple forms of aortic and cartilage lysyl oxidase and a catalytically quiescent aortic protein. J Biol Chem 257: 13520-13526, 1982.

24. Kuivaniemi H, Savolainen ER and Kivirikko KI: Human placental lysyl oxidase. Purification, partial characterization, and preparation of two specific antisera to the enzyme. J Biol Chem 259: 6996-7002, 1984.

25. Li W, Nellaiappan K, Strassmaier T, Graham L, Thomas KM and Kagan HM: Localization and activity of lysyl oxidase within nuclei of fibrogenic cells. Proc Natl Acad Sci USA 94: 12817-12822, 1997.

26. Cronshaw AD, Fothergill-Gilmore LA and Hulmes DJS: The proteolytic processing site of the precursor of lysyl oxidase. Biochem J 306: 279-284, 1995.

27. Hayashi K, Fong KS, Mercier F, Boyd CD, Csiszar K and Hayashi M: Comparative immunocytochemical localization of lysyl oxidase (LOX) and the lysyl oxidase-like (LOXL) proteins: changes in the expression of LOXL during development and growth of mouse tissues. J Mol Histol 35: 845-855, 2004.

28. Mello ML, Contente S, Vidal BC, Planding W and Schenck U: Modulation of ras transformation affecting chromatin supraorganization as assessed by image analysis. Exp Cell Res 220: 374-382, 1995.

29. Kirschmann DA, Seftor EA, Nieva DR, Mariano EA and Hendrix MJ: Differentially expressed genes associated with the metastatic phenotype in breast cancer. Breast Cancer Res Treat 55: 127-136, 1999.

30. Stassar MJ, Devitt G, Brosius M, Rinnab L, Prang J, Schradin T, Simon J,Petersen S, Kopp-Schneider A and Zoller M: Identification of human renal cell carcinoma associated genes by suppression subtractive hybridization. Br J Cancer 85: 1372-1382, 2001.

31. Ren C, Yang G, Timme TL, Wheeler TM and Thompson TC: Reduced lysyl oxidase messenger RNA levels in experimental and human prostate cancer. Cancer Res 58: 1285-1290, 1998.

32. Woznick AR, Braddock AL, Dulai M, Seymour ML, Callahan RE, Welsh RJ, Chmielewski GW, Zelenock GB and Shanley CJ: Lysyl oxidase expression in bronchogenic carcinoma. Am J Surg 189: 297-301, 2005

33. Kaneda A, Wakazono K, Tsukamoto T, Watanabe N, Yagi Y, Tatematsu M, Kaminishi M, Sugimura T and Ushijima T: Lysyl oxidase is a tumor suppressor gene inactivated by methylation and loss of heterozygosity in human gastric cancers. Cancer Res 64: 6410-6415, 2004.

34. Kirschmann DA, Seftor EA, Fong SF, Nieva DR, Sullivan CM, Edwards EM, Sommer P, Csiszar K and Hendrix MJ: A molecular role for lysyl oxidase in breast cancer invasion. Cancer Res 62: 4478-4483, 2002.

35. Palamakumbura AH, Jeay S, Guo Y, Pischon N, Sommer P, Sonenshein GE and Trackman PC: The propeptide domain of lysyl oxidase induces phenotypic reversion of ras-transformed cells. J Biol Chem 279: 40593-40600, 2004.

36. Min C, Yu Z, Kirsch KH, Zhao Y, Vora SR, Trackman PC, Spicer DB, Rosenberg L, Palmer JR and Sonenshein GE: A lossof-function polymorphism in the propeptide domain of the LOX gene and breast cancer. Cancer Res 69: 6685-6693, 2009.

37. Zhao Y, Min C, Vora SR, Trackman PC, Sonenshein GE and Kirsch KH: The lysyl oxidase pro-peptide attenuates fibronectinmediated activation of focal adhesion kinase and p130Cas in breast cancer cells. J Biol Chem 284: 1385-1393, 2009.

38. Palamakumbura AH, Vora SR, Nugent MA, Kirsch KH, Sonenshein GE and Trackman PC: Lysyl oxidase propeptide inhibits prostate cancer cell growth by mechanisms that target FGF-2-cell binding and signaling. Oncogene 28: 3390-3400, 2009. 